\title{
¡UN AÑO PARA CAMINAR UNIDOS Y TRABAJAR JUNTOS!
}

DOI: https://doi.org/10.52039/seminarios.v49i169.810

Autor: Antonio Ladisa. Vicedirector del CNV.

Recogiendo el transcurso del Congreso, enfoca con la memoria de los comienzos y la trayectoria en estos años desde 1985, paa recordarnos que no se parte de cero, sino que hemos de coordinar nuestras pastoral con fines, lugares y objetivos contextuales y definidos.

Hemos llegado a la conclusión de este Convenio Nacional, abierto oficialmente el 2 de enero, pero que, podemos decir, inició su camino hace exactamente un año, durante el Congreso anterior. En aquella circunstancia tanto el cardenal Ruini, como Mons. Bettori en su homilía nos habían exhortado a poner en práctica lo que está escrito en las Orientaciones Pastorales de la CEI para este primer decenio del 2000: "Advertimos la necesidad de promover una mayor coordinación entre la pastoral juvenil, la pastoral de la familia y la vocacional: el tema de la vocación es, en efecto, totalmente central para la vida de un joven" 1 . El CNV no sólo ha prestado atención a esta sugerencia, sino que ha querido retomar también en el tema de este Congreso algunas indicaciones de los Obispos italianos, dando de esta manera una primera respuesta -que ciertamente no será la única- a cuanto se nos ha pedido.

Creo que a ninguno ha pasado desapercibida la apostilla adjunta a la frase de las Orientaciones Pastorales, escrita en el cartel que está encima del

\footnotetext{
${ }^{1} \mathrm{CEI}$, Comunicar el Evangelio en un mundo que cambia, 51.
} 
palco y que reproduce el tema del Congreso: Propiciar una mayor coordinación entre la pastoral juvenil, la pastoral de la familia y la vocacional... ¿Cómo?

Este “¿Cómo?” no constituye, sin embargo, una novedad, porque, como todos saben, este adverbio está modulando ya desde el 2000 nuestros Congresos Nacionales.

Después de la etapa de los Congresos "de estudio", que nos han acompañado además durante veinte años, no hemos querido inaugurar las de los Congresos interesados exclusivamente por la praxis. Como se recordará, este cambio se quiso no ciertamente para separar la reflexión teológica del hace pastoral, sino, al contrario, para hacer que la extraordinaria riqueza de los contenidos, que emergen siempre de nuestros Congresos, no sea riqueza exclusiva de este grupo cerrado, aunque numeroso, de congresistas o sellada "para futura memoria" en las Actas, sino que se extienda hasta las mil orillas de la pastoral vocacional de nuestras comunidades cristianas, iluminándola y renovándola.

Al término de este Congreso se abre ante nosotros un nuevo año. Volvamos hoy a las cosas de siempre, pero ¡no como siempre! Queremos, en efecto, que alguna cosa cambie en nuestra actividad pastoral, también a la luz de cuanto hemos rezado, oído de los conferenciantes, reflexionado personalmente y hecho objeto de discusión y de esclarecimiento en los grupos de estudio.

A mí en este momento no me queda otra cosa que sacar los hilos de cuanto se ha presentado en estos días y relanzarlo aquí en la asamblea para que el nuevo año nos sorprenda empeñados en caminar unidos y trabajar juntos a partir de algunos puntos fundamentales. Entonces, pues jun nuevo año unidos!

Quisiera subdividir mi intervención en dos partes: en la primera señalaré algunas actitudes que hay que abandonar; en la segunda ofreceré algunas indicaciones pastorales para el nuevo año.

\section{No estamos en el año cero}

Empiezo citando a Friedrich Hebbel: "A la juventud se le reprochará a menudo el creer que el mundo comienza solo con ella. Pero la vejez cree también con más frecuencia que el mundo se acaba con ellos".

La primera actitud que hemos de tomar es la de abandonar eso de que nos encontramos en el año cero y que sólo ahora se comienza por fin a hablar de la necesaria coordinación entre la pastoral juvenil (PJ), la pastoral familiar (PF) y la pastoral vocacional (PV). Y cuanto sucede al término de este Congreso: todo congresista, fascinado por todo lo nuevo que los expertos le han hecho descubrir, se separa del camino hecho y, como un nuevo Sísifo, descubre cada año cómo conseguir llevar desde el fondo del valle hasta la cima de la colina el enorme pedrusco de la pastoral vocacional, que después, al final del año, 
vuelve inevitablemente abajo. La memoria nos ayuda a construir sobre lo que ya está hecho; la ausencia de memoria lleva a la frustración y al desánimo.

Es, por lo tanto, necesario purificar la memoria.

Recorramos ahora, aunque sea sólo con breves trazos, las grandes etapas de este camino, ya recorrido, en el que la PV ha sido llamada a prestar cada vez más una mayor atención al mundo juvenil y al mundo familiar. Haremos juntos este camino no limitándonos a poner en evidencia los logros y las propuestas pastorales más significativas de estos últimos veinte años, sino buscando recoger ya las provocaciones del Espíritu, ya las respuestas que la Iglesia ha sabido dar. Convencidos como estamos de que"en todo tiempo tú [el Señor] das nueva energía a tu Iglesia y a lo largo de su camino la guías y proteges admirablemente. Con el poder de tu Santo Espíritu le aseguras tu sostén, y ella, en su amor confiado, no se cansa jamás de invocarte en la prueba y en la alegría siempre te da gracias por medio de Cristo nuestro Señor"2.

\section{5}

El año 1985 está marcado por la publicación de Plan Pastoral de las vocaciones en Italia que en diversos números $(33,34,37,43,54)$ 1lama la atención a los animadores vocacionales sobre la necesidad de colaborar con la PJ. Y en el número 43 se expresa de esta manera: "La pastoral juvenil debe ser vocacional: pastoral juvenil y pastoral vocacional son complementarias. La pastora específica de las vocaciones encuentra en la pastoral juvenil su espacio vital. La pastoral juvenil se halla completa y eficaz cuando se abre a la dimensión vocacional".

En este mismo año el Papa escribe la Carta a los jóvenes. En toda la Carta Juan Pablo II pone en claro la dimensión vocacional que es el eje transversal de la vida de los jóvenes. En dos números, sin embargo, más que en los otros, el Papa se detiene a hablar del proyecto de la vida y de la vocación cristiana (n. 9) y de la vocación matrimonial (n. 10). Más allá del contenido, importante de por sí, el primer gran fruto que esta Carta produjo fue el de suscitar en el interior de la comunidad cristiana un renovado y confiado compromiso educativo a favor de los jóvenes. Las Jornadas Mundiales de la Juventud viene a ser como un especie de peregrinación espiritual del Papa con los jóvenes no sólo por los caminos del mundo, sino sobre todo en los recovecos de su corazón para hacer salir aquella riqueza depositada en él por el Señor y que está esperando ser descubierta y que se la haga fructificar.

${ }^{2}$ Prefacio IX de los domingos del tiempo ordinario. 
El CNV en aquellos años dedicaba a los jóvenes dos Congresos Nacionales: "Jóvenes hoy: ¿qué propuesta vocacional?" (1984); "Jóvenes hoy: de la percepción a la elección vocacional” (1985).

1990

Podemos afirmar sin duda alguna que los años $90^{\circ}$ han sido los más fecundos.

Las Orientaciones Pastorales de la CEI: Evangelización y testimonio de la caridad dedican a los jóvenes tres números (44-46); no parecen poca cosa. Basta pensar que en las Orientaciones del decenio precedente (Comunión y Comunidad) se señalaba a los jóvenes sólo en dos números: 23 y 26, pero con brevísimos pasajes. En ETC la reflexión es más articulada y completa. En el número 46 los Obispos hablan de la resonancia constitutiva vocacional de la PJ y afirman: "La vocación cristiana es fundamentalmente única y coincide con el seguimiento de Cristo y de la caridad. Estamos, no obstante, llamados a vivir esta misma vocación mediante diversos caminos: en el camino del matrimonio y del compromiso laical, o en el presbiterado, de la vida religiosa, de los institutos seculares y otras formas de especial entrega. Nos volvemos con confianza a los jóvenes y a las jóvenes, porque saben apuntar a lo alto y no tienen miedo de seguir con generosidad el camino de la consagración total a Dios, cuando advierten su 1lamada, respondiendo al amor con el amor. Subrayemos al mismo tiempo que la educación a la gratuidad y al servicio por el reino de Dios es el terreno común sobre el cual pueden florecer las múltiples vocaciones eclesiales"3.

Para actualizar cuanto estaba escrito en algunos números de las Orientaciones, surge el Servicio Nacional de Pastoral Juvenil (1993), confiado al infatigable y contagioso entusiasmo de Don Domenico Sigalini. En diversas circunstancias el CNV y el Servicio de Pastoral Juvenil se han encontrado unidos para reflexionar y diseñar una acción común a favor de los jóvenes. Es cuanto se trata en el Encuentro bienal de los Directores de los CDV de septiembre de 1993 que tenía como tema "La constitutiva resonancia vocacional en la educación de los jóvenes a la fe". Dos años después, en el Encuentro de octubre de 1995 se comprometió también a la Caritas nacional en la reflexión con el tema "El Evangelio de la caridad llama a los jóvenes". También anteriormente, en septiembre de 1987, el Encuentro de los Directores se había detenido sobre la pastoral juvenil: "La dimensión vocacional en la pastoral juvenil: verificación de iniciativas y propuesta de caminos".

${ }^{3} \mathrm{CEI}$, Evangelizzacione e testimonianza della carità, 46. 
Como se puede notar bien, tenemos ya a nuestras espaldas un camino hecho juntos que, quizás, está reasumido y, ciertamente, relanzado.

1993

En julio de 1993 sale publicado el Directorio de Pastoral familiar (DPF), que, aunque de por sí no se ocupa exclusivamente de los jóvenes y de las vocaciones, sin embargo les reserva una constante atención. Es, no obstante, en el segundo capítulo: "Vocación al amor", donde el tema vocacional es desarrollado con una riqueza y profundidad sorprendente.

En la profundización del Directorio el CNV dedicó un número de la revista "Vocazioni". "Vocación y vocaciones en la pastoral familiar de la Iglesia italiana" (n. 5, 1997) un reflexión que había sido ya precedidas de un número de la misma revista. "La pastoral familia y vocacional" (n. 3, 1992), Y en un Congreso Nacional: "Familia hoy: qué espacio para la maduración vocacional" (enero, 1990).

No se pueden pasar por alto algunas afirmaciones, presentes en los números 23-30 del DPF, que constituyen los puntos indiscutibles de la PF y PV:

"Es en la óptica de la vida como vocación al amor como adquiere valor y significado la pastoral familiar y es en la educación a la vida y al amor donde se inicia todo itinerario de pastoral familiar" (n. 23).

Y citando a la Familiaris consortio (n.11) prosigue: "El amor es, por lo tanto, la fundamental y original vocación de todo ser humano” (n. 23).

El número 23 concluye con una cita de la Encíclica Redemptor hominis (n. 10) de Juan Pablo II: "El hombre no puede vivir sin amor. Ellos permanecen por sí mismo un ser incomprensible, su vida está privada de sentido, si no le viene revelado el amor, si no se encuentra con el amor".

En el número 24 se recuerda que "esta original y fundamental vocación al amor, propia de cada hombre y de cada mujer, puede realizarse plenamente en el matrimonio y en la virginidad".

Es en el número 28, sin embargo, donde emerge con fuerza la dimensión vocacional: "Se trata de ayudar a cada uno a madurar en aquella libertad radical, que consiste en decidir sobre sí mismo según el proyecto que Dios inscribe en el ser del hombre, siguiendo el ejemplo y la medida de Jesús, a cuya imagen estamos destinados a parecernos (cf. Rm 8, 28-30). En esta perspectiva toda acción educativa posee una intrínseca dimensión vocacional propia: es ayuda ofrecida a cada uno para que pueda descubrir y seguir su vocación fundamental al amor en el matrimonio o en la virginidad, cumplimiento de la consagración bautismal, y vivir así su misión en la Iglesia y en el mundo". 


\section{8-1999}

Este nuestro breve viaje para "purificar la memoria" nos conduce a una etapa extremadamente significativa: las dos Asambleas de los Obispos italianos de noviembre de 1998 y de mayo de 1999. Dos momentos de una única gran reflexión dedicada por los Obispos a la PJ y a la PV. En estas dos Asambleas se han originado a continuación dos Notas Pastorales de la CEI que han retomado y relanzado las reflexiones e indicaciones de los Obispos italianos: "Educar a los jóvenes en la fe" (1998) y "La vocación al ministerio ordenado y a la vida consagrada en la comunidad cristiana" (1999). Me limito a citar solamente dos frases de estos dos documentos: "Es necesario iniciar a los jóvenes a la vida como respuesta a una vocación, ayudándoles a ver que su camino de seguimiento a Cristo se va realizando concretamente en un estado de vida, sin temor de hacer propuestas exigentes y mostrando que para todos hay una llamada y un proyecto de santidad. Es siempre la perspectiva vocacional que permite entender y evaluar la experiencia del voluntariado, descubriendo las raíces en el misterio mismo del amor de Dios"4. "El Centro Diocesano de Vocaciones... promueve itinerarios vocacionales específicos y coordina las iniciativas de pastoral vocacional existentes en la Iglesia particular; forma los animadores vocacionales y tiene cuidado de que en el pueblo de Dios se difunda una cultura vocacional; participa en la elaboración del proyecto pastoral diocesano y colabora en particular con la pastoral familiar y con la juvenil"5.

\section{1}

Y henos aquí juntos en el documento de la CEI "Comunicar el Evangelio en un mundo que cambia" que está orientando no solo el camino de la Iglesia italiana en este primer decenio del 2000, sino desde el que hemos querido traer el tema de este nuestro Congreso. El contexto inmediato que da sentido y significado a la invitación dirigida por los Obispos a "favorecer una mayor coordinación entre la PJ, PF y PV"(CVC 51), es el de la llamada del episcopado italiano a prestar "una atención particular a los jóvenes y a la familia. Este es el compromiso que confiamos y recomendamos a la comunidad cristiana"6. Además, se nos ha pedido hacer converger la atención de la PJ, PF y PV en las personas, más que preocuparse de coordinar las iniciativas.

4 CEI: Educar a los jóvenes en la fe, 2.

5 CEI: Las vocaciones al ministerio ordenado y a la vida consagrada en la comunidad cristiana, 25.

6 CEI: Comunicar el Evangelio en un mundo que cambia, 51. 


\section{No estamos bajo cero}

En el peligro, siempre al acecho, de convertirnos en pioneros y de volver a invocar nuevos sentimientos, se contrapone el otro, no menos insidioso, de quedar "congelados" en las propias posiciones, haciendo así imposible cualquier tentativa de cambio en la pastoral.

Esta incapacidad para salirse, aunque sea un poco, de lo "que siempre se ha hecho" y de ponerse en camino sobre la carrera de una auténtica renovación pastoral, asume, según los casos, nombres y rostros diversos, pero todos inexorablemente inclinados al inmovilismo.

- Se sigue actuando como si el mundo no hubiese hecho cambio, con la secreta esperanza de que, al final, necesariamente el mundo deberá volver a nosotros. Y en el entretiempo... se queda inmóvil, como "término fijo de eterno consejo".

- Se hacen lecturas simples de nuestra sociedad evitando la complejidad o tentando remover los problemas. Con tal de no cambiar está dispuesto a cerrarse en vivir en una isla feliz, todavía no contaminada con cuanto en otra ciudad ha traído la descristianización.

La expresión del CVMC que nos ha guiado en este Congreso, sin la referencia a todo este camino recorrido ya por la Iglesia italiana, correría el riesgo de ser muy pobre y de dar vida a una simple coordinación de iniciativas. Los Obispos no han pedido a la PF, a la PJ y a la PV que firmen una especie de "pacto de estabilidad", o "pacto social". Aquí, como nos ha recordado el cardenal Ruini en su homilía, está en juego la transmisión de la fe y de los estilos de vida cristiana a las jóvenes generaciones. Y en esta fascinante y comprometida tarea no podemos no comprometernos en realizar la unión de fuerzas, que hace posible el logro de este objetivo.

Del resto: en estos días se nos ha recordado que difícilmente lograríamos realizar esta auspiciada coordinación, si estuviéramos preocupados únicamente de poner en el centro nuestra acción pastoral y nuestras Oficinas, en una especie de autorreferencialidad; o más si nos ponemos en la continua búsqueda de reconocimiento, de estima y de espacios de intervención, refugiados en el deseo de ejercicio: o, por fin, si intentáramos pasar a los otros la responsabilidad si no se logra una eficaz colaboración.

- La coordinación exige una "conversión pastoral" y es fruto de una conversión pastoral ya conseguida. En el centro no ponemos nuestras actividades y nuestros Centros, nuestras iniciativas, sino que en el centro es necesario colocar las personas: los jóvenes y las familias.

Hemos iniciado este Congreso acogiendo la petición que Mons. Castellani ha hecho resonar en la oración inicial: “¿Cómo puede un joven vivir bien su vida? 
El acuerdo entre la PJ, PF y PV será posible si conservamos siempre viva en nosotros esta pregunta: ¿Cómo podemos ayudar a los jóvenes a vivir su vida?'. Sí, queremos que los jóvenes que encontremos puedan percibir nuestra voluntad de ser colaboradores de su alegría evitando hacer de patronos de su fe (cf. 2 Cor 1, 24).

Sólo si nos ponemos todos al servicio de la felicidad de los jóvenes, buscaremos de todos modos hacer converger nuestras competencias y nuestra acciones para que todo joven pueda ser ayudado a encontrar la respuesta a esa petición que alberga en su corazón: "¿Qué debo hacer para tener vida?"

\section{Favorecer una mayor coordinación entre PJ, PF y PV. Sí, pero... ¿Cómo?}

La llamada de los Obispos a realizar una mayor coordinación entre la PJ, PF y PV se inserta en el contexto de las Orientaciones Pastorales para este primer decenio; sacándolo de este su natural contexto, su acogida resultaría extremadamente reducida. La novedad de estas Orientaciones no está solamente en el renovado compromiso de "comunicar el evangelio". Es éste un compromiso que acompaña a la Iglesia desde su principio y después del Concilio ha sido relanzado con fuerza. Para confirmar esto, sería suficiente con citar dos documentos: "La Iglesia es por naturaleza misionera"7; "La evangelización es la gracia y la vocación de la Iglesia... Ella existe para evangelizar". La novedad, si os parece, se encuentra sobre todo en la segunda parte del Documento: "en un mundo que cambia". Un cambio que atañe a la sociedad entera y no solo a algunos sectores. Por esto, nos dicen los Obispos, si queremos "comunicar el Evangelio", necesariamente debemos sintonizar con "un mundo que cambia” rápidamente. En una palabra: ¡escuchar! ésta es la sólida llamada que nos viene de las Orientaciones; basta pensar que la palabra "escuchar" sale, aproximadamente, 56 veces.

Desde el comienzo de este Documento los Obispos italianos indican con claridad que la primera y necesaria actitud a asumir es precisamente la de la escucha: "Preferimos hacer muchas cosas, o buscar distracciones. Sin embargo son la escucha, la memoria y el pensar en descubrir el futuro, a ayudarnos a vivir el presente no solo como tiempo de satisfacción de las necesidades, sino también como lugar de espera, del manifestarse del deseo que nos precede y nos conduce más allá, llegándonos a los otros hombres y convirtiéndonos todos en compañeros en el maravilloso y misterioso viaje que es la vida".

${ }^{7} \mathrm{AG}, 2$.

$8 \mathrm{EN}, 14$.

${ }^{9}$ CEI: Comunicar el evangelio en un mundo que cambia, 2. 
Comprendemos ahora por qué en todas las relaciones ha resonado, como un martilleante ritornello, la invitación a ponerse a la escucha. Y el padre Cencini nos ha recordado que la cualidad de nuestra pastoral deriva directamente de la cualidad de nuestra escucha.

No dejamos de reconocer que la escucha es siempre arriesgada; por esto preferimos escaparnos sumergiéndonos en la acción, antes que reservar espacio para la reflexión. "La raíz de la fe bíblica está en la escucha, actividad vital, pero exigente. Porque escuchar significa dejarse transformar, poco a poco, hasta ser conducidos a través de caminos diversos de los que hayamos podido imaginar buscándonos en nosotros mismos" 10 .

- Una primera e importante forma de coordinación entre la PJ, PF y PV podrá ser la de crear los "Observadores en el terreno", tal como se auspiciaba en el Congreso eclesial de Palermo, capaces de percibir los cambios y de ofrecer las adecuadas indicaciones pastorales. "La comunidad cristiana debe constituir el ámbito en el que se da el discernimiento comunitario, indicado en el Congreso eclesial de Palermo de 1995 como escuela de comunión eclesial y método fundamental para la relación Iglesia-mundo"11.

\section{¿Para qué?}

En una "cultura antivocacional", donde se va delineando el rostro de un hombre "sin vocación", no nos podemos permitir el lujo de permanecer quietos a la espera de tiempos mejores. Se hace necesario dedicarse activamente para orientar en un sentido cristiano la cultura con el convencimiento -como nos ha recordado el Papa en el Congreso eclesial de Palermo- de que "un evangelio que no se incultura no es plenamente escuchado ni totalmente pensado y vivido, y una cultura que no trae en la fe apertura y corrección inéditas no está en disposición de responder a las exigencias más profundas de la persona".

En efecto, la escucha que se nos ha propuesto en las Orientaciones, se debe expresar necesariamente en una doble dirección: "Si queremos adoptar un criterio oportuno por el cual dejarnos guiar para llevar a cabo un discernimiento evangélico, debemos cultivar dos atenciones entre sí complementarias" 12 .

"La primera consiste en el esfuerzo por situarse a la escucha de la cultura de nuestro mundo, para discernir las semillas del Verbo ya presentes en la misma, más allá de los límites visibles de la Iglesia. Escuchar la esperanza más íntima de nuestros contemporáneos, tomar en serio deseos y búsque-

\footnotetext{
${ }^{10}$ Ibidem, 13.

${ }^{11}$ Ibidem, 50.

12 Ibidem, 34.
} 
das, buscar entender qué hace arder los corazones y qué, a su vez, suscita en él tristeza y desconfianza, es importante para podernos hacer siervos de su alegría y de su esperanza"13. La escucha atenta de la cultura presente en nuestra sociedad nos lleva a afirmar que nos encontramos ante un cambio antropológico. Los obispos italianos han tenido el cuidado de detenerse en reflexionar sobre esta temática en las últimas dos Asambleas ${ }^{14}$. El cuadro cultural actual se va separando de su referencia a las raíces evangélicas y toma carta de naturaleza una nueva visión del hombre. "ya en el por lo demás lejano 1975 Pablo VI advertía a la Iglesia entera a reconocer que la ruptura entre el Evangelio y la cultura era, más que cualquier otro, el drama por excelencia de nuestra época. Los cristianos pueden fecundar el tiempo en el que viven solo si están continuamente atentos para acoger los desafíos que provienen de su historia, y se ejercitan en responder conforme a la luz del evangelio"15.

¿Qué hacer? No podemos limitarnos a ser espectadores pasivos del cambio. Es cuanto viene a afirmar el cardenal Ruini: "Quisiera ante todo expre-

13 Ivi.

14 Superado el peligro de la antropología claramente dualista, se asiste al difundirse de orientaciones con una fuerte caracterización naturalista, en la que la unidad del sujeto humano es fruto de su reducción a la dimensión racional únicamente. A esto contribuyen ciertas interpretaciones de los resultados de la investigación neurológica, como determinadas teorías sobre la llamada 'inteligencia artificial'. La consiguiente visión cientifista del hombre entra en conflicto con la conciencia cristiana de la persona humana, en cuanto que constituye una práctica negación de su transcendencia y de su llamada a una vida personal más allá de la muerte" (Comunicado final del Consejo permanente de enero 2002).

Si he subrayado antes, que después del pluralismo religioso, la cuestión más radical y más cargada de consecuencias para la pastoral es la 'cultural'; la centralidad cristológica pide una reflexión antropológica. El mismo Cardenal Presidente, en su introducción, ha puesto el acento en la cuestión antropológica, porque la actual cultura pragmática y cientifista, a diferencia del pasado, aún no lejano, tiende no sólo a interpretar al hombre sino sobre todo a transformarlo" (Comunicado final del trabajo de los Obispos Italianos, XLIX Asamblea General).

El haber puesto en el centro del debate de la asamblea la cuestión antropológica ha determinado también una convergencia sobre la prioridad, en continuidad con las Orientaciones pastorales para este decenio: necesidad de prestar mayor atención a aquellos que actúan en el campo de la investigación y la divulgación científica, como consecuencia de una pastoral de la inteligencia'...; ánimo a los jóvenes para mirar los estudios científicos y la alta investigación como ámbitos de particular relevancia para el testimonio de la fe; asunción de la fórmula de diálogo y de la investigación propuesta en el proyecto cultural como paradigma permanente para promover, también en el ámbito local, la confrontación con los exponentes del mundo científico; educación de los creyentes en la capacidad de conjugar la experiencia de la fe con la necesidad de dar razón de la esperanza cristiana, utilizando todos los instrumentos que la ciencia pone hoy a disposición del hombre" (Comunicado final de los trabajos de la XLIX Asamblea General de los Obispos italianos).

15 CEI, Comunicar el Evangelio en un mundo que cambia, 50. 
sar mi convencimiento de que tales mutaciones no se pueden parar ni darles la vuelta, al menos en el aspecto no accidental ni secundario por el cual se radican en la razón científico-técnica: una batalla en este sentido estaría ya de partida perdida. Pero eso no significa que los cambios mismos no puedan ser orientados desde un cristianismo "enteramente pensado y fielmente vivido" -por usar las palabras del papa en el discurso de 1982 en el Congreso nacional del MEIC-, capaces como tal de influir también en las formas, y sobre todo, en la interpretación del conocimiento científico y técnico, para hacerlo más abierto y al mismo tiempo más consciente de sus propios límites... es posible una crítica de la actual cultura 'pública' y de su distancia de la vida en la pretensión de reducir el cristianismo a una mera herencia cultural, disponible para todos los usos"16. Y el Secretario general de la CEI observa: "Nos encontramos frente al desafio por el cual, si no queremos reducir nuestra presencia en la historia a la de una pequeña grey-poco importante y necesaria en su función de signo- sino que queremos llegar a dar testimonios eficaces en orden al influjo que el evangelio puede y debe tener en el modelar el ethos civil, tenemos necesidad de preguntarnos qué rostro debe asumir una comunidad cristiana que quiera hacer preceder (para preparar el terreno) y hacer seguir (para hacer patentes los frutos) el anuncio de la palabra y la celebración del misterio en una acción culturalmente significativa, en cuanto plausible y signo fascinante como proyecto" 17 .

- Y en dos Mensaje para la Jornada Mundial de Oración por las Vocaciones el Papa nos ha animado a asumir seriamente este compromiso. "Es necesario promover una cultura de la vocación que sepa reconocer y acoger la aspiración más profunda del hombre, que lo lleve a descubrir que solo Cristo puede decirle toda la verdad sobre su vida... esta cultura de la vocación está en la base de la cultura de la vida nueva, que es vida de gratitud y de gratuidad, de confianza y de responsabilidad; en la raíz, esa es la cultura del deseo de Dios, que da la gracia de apreciar al hombre por sí mismo, y de reivindicar incesantemente la dignidad frente a todo aquello que puede oprimir en el cuerpo o en el espíritu"18. "La escucha de la Revelación divina, la meditación silenciosa, la oración de contemplación y su traducción en experiencia de vida constituyen el terreno en el cual florece y se desarrolla una auténtica cultura vocacional"19.

16 Card. Camilo Ruini, Relazione introduttiva al terzo Forum del progetto culturale, svoltosi a Pieve di Cento (BO) il 24 e 25 marzo de 2000.

17 G. Bettori, Il tema del Convengo eclesiale Nazionale. Asamblea General de la CEI: Collevalenza, 18.21 nov. 2002.

18 JUAN PABLO II, Mensaje para la XXX Jornada MOV, 2.

19 JUAN PABLO II, Mensaje para la XXXIV JMOV, 3. 
Y en este compromiso, que envuelve necesariamente toda la comunidad cristiana, la PJ y la PV están llamadas a coordinar más su acción.

- Todavía otro objetivo sobre el que están llamadas a converger las tres pastorales. Se hace necesario sobre todo favorecer una mayor implicación de nuestra comunidad en el proyecto cultural y calificar e intensificar la presencia cristiana en la escuela, como nos ha dicho repetidas veces Mons. Lanza.

Significativo es a tal propósito cuanto se ha afirmado en un reciente documento: "La promoción de una nueva cultura vocacional es un componente fundamental de la nueva evangelización. A través de ella necesita hacer "encontrar coraje y gusto por las demandas grandes, algunas relativas al propio futuro".

Son peticiones que se van despertando también a través de currículos educativos personalizados por medio de los cuales conduce progresivamente a descubrir la existencia como don de Dios y como realización. Tales recorridos pueden configurar un verdadero itinerario de maduración vocacional, que lleve al descubrimiento de una vocación específica. Las personas consagradas son particularmente llamadas a promover en la escuela la cultura de la vocación. Son un signo para todo el pueblo cristiano no sólo de una determinada vocación, sino también del dinamismo vocacional como forma de vida, representando de manera elocuente la decisión de quien quiere vivir atento a la llamada de Dios"20.

\section{¿Con qué objeto?}

¿A dónde debe dirigirse la coordinación entre PJ, PF y PV? Ante todo "Partir de Cristo", esto es, favorecer el encuentro de los jóvenes con Cristo.

"La atención a lo que emerge en la búsqueda del hombre no significa renuncia a la diferencia cristiana, a la transcendencia del Evangelio, por afirmación a las esperanzas más inmediatas de una época o de una cultura... hay una novedad irrenunciable en el mensaje cristiano: aunque indicando un camino de plena humanización, no se limita a proponer un mero humanismo" 21.

"Llevar los jóvenes a Cristo" ha sido también la llamada repetida con fuerza en estos días primero por el cardenal Ruini, también por el cardenal Grocholewski en su homilía. Ellos han hecho resonar en nuestras celebraciones cuanto escribía el Papa: "«Y lo conduce a Jesús». Está aquí, en cierto sentido, el corazón de toda la pastoral vocacional de la Iglesia, con la cual ella toma a su cargo el nacimiento y el desarrollo de la vocación, sirviéndose de

20 CONGREGAZIONE PER L'EDUCAZIONE CATÓLICA, Le persone consacrate e la loro mission nella scuola, 56.

${ }^{21} \mathrm{CEI}$, Communicare il Vangelo in un mondo che cambia, 53. 
los dones y de la responsabilidad, de los carismas y del ministerio recibido de Cristo y de su Espíritu"22. Y Mons. Betori en su homilía nos ha puesto en guardia para que no reduzcamos el cristianismo a una simple propuesta de valores, sin que emerja cada vez con mayor claridad la identidad de Cristo y la decisión de seguirlo. Recordamos lo que han escrito los Obispos italianos: La experiencia cristiana no es una genérica propuesta de valores, y ni siquiera una ética del amor: es encuentro decisivo y concreto con Jesucristo. Un encuentro que permite reconocer a Jesús como Maestro y Señor y a sí mismo como discípulos. Creer supone por su propia naturaleza un proyecto global de vida... La praxis pastoral debe favorecer este encuentro personal con Cristo e ir más allá de las propuestas genéricas. En particular la pastoral juvenil creciendo genera la propuesta vocacional específica"23. Y Juan Pablo II en la Novo millennio ineunte ha recalcado con fuerza: "No nos salvará una fórmula, sino una persona: Jesucristo". No se puede dar por descontado, como a veces sucede, que los jóvenes hayan elegido a Cristo y se comprometan a seguirlo (cf. RdC 57), aunque frecuenten nuestros grupos y nuestra comunidad. Los Obispos italianos han lanzado un grito de alarma por "el creciente analfabetismo religioso de las generaciones jóvenes, por tantos lados bien dispuestos y generosos, pero igualmente no adecuadamente formados en lo esencial de la experiencia cristiana y aún menos en una fe capaz de hacerse cultura y de tener peso en la historia"24. Es necesario evangelizar porque -como afirmó el cardenal Tettamanzi en el Sínodo europeo-. "Si en el pasado se bautizaban los convertidos, ahora necesitamos convertir a los bautizados". Por lo demás los Obispos italianos han afirmado recientemente que "la misión ad gentes no es solamente el punto conclusivo de la tarea pastoral, sino su constante horizonte y su paradigma por excelencia" 25 .

- Por lo tanto la primera preocupación de todo educador en la fe, sobre todo de los animadores vocacionales, debe ser no tanto la de informar, cuanto la de ayudar a los jóvenes a dejarse "conformar por Cristo, hasta asumir su mismo sentir" (cf. Fil 2, 5)"26.

¿Y dónde se presenta Cristo con toda su fuerza rompedora capaz de convulsionar los pequeños proyectos de vida condicionados por el subjetivismo y el hedonismo, o agazapados en el presente, abriendo para cada bautizado caminos inéditos de vida en su caminar? ¡En la Cruz! En efecto, "la cruz ha

22 Juan PABLO II, PDV, 38.

23 CEI. Le vocazioni al ministero ordinato ed alla vita consacrata nella comunita cristiana, 5 .

${ }^{24} \mathrm{CEI}$, Comunicare il Vangelo in un mondo che cambia, 40.

25 Ibidem, 32.

26 Ibidem, 33. 
llegado a ser la suprema cátedra para la revelación de su nacimiento y de su impredecible identidad: el rostro del amor que se entrega y que salva al hombre condonando totalmente la condición, «excluido el pecado» ( $\mathrm{He} \mathrm{4,15).} \mathrm{La}$ Iglesia no debería olvidarlo jamás: será este su camino al servicio del amor y de la revelación de Dios a los hombres"27. Todo educador cristiano que acompaña a los jóvenes en su camino hacia la madurez de fe-vocación no podrá jamás evitar detenerse juntos con su Calvario y "volver la mirada a Aquel a quien han traspasado" (Jn 19,37). De la cruz sale el camino que conduce al creyente a la auténtica realización: "en el don sincero de sî" (GS 24).

\section{¿Cuándo?}

¿Cuándo comenzar a ayudar a los bautizados a asumir como estilo de su vida la lógica de la entrega? Conscientes de que esto no es una actitud que se pueda improvisar, se hace indispensable hacer converger nuestras fuerzas y nuestras acciones para que desde el principio sean las familias los lugares en los cuales el niño desde el mismo momento de su nacimiento pueda experimentar el ser acogido, querido y amado, y también sea ayudado a entrenarse a saber amar con un corazón limpio: "La importancia del espacio educativo familiar, en el que crece y madura toda clase de vocación, pide establecer un puente claro entre la pastoral familiar y la pastoral vocacional, para una reciproca fecundidad" 28 . Es lo que nos ha recordado don Nicolli, director de la Oficina para la PF.

La vocación, lejos de ser un camino recorrido en solitario con la manía de la perfección y la constante preocupación de "salvar el alma", provoca a todos a caminar junto al hermano haciendo resplandecer, en la fidelidad a la vocación recibida, el rostro del Amor. "A la revelación del rostro de Dios nosotros podemos contribuir por la gracia, en la convicción de que en este trabajo del anuncio nosotros mismos profundizamos en su conocimiento"29. En efecto, "toda forma de amor, -el perdón, el don de sí, el compartir, y otras mil cosas-es el lugar en el cual se vislumbra para cada uno de nosotros cualquier ración de eternidad. Porque la vida eterna es el amor"30. El amor es pues el corazón latente en toda vocación.

No podemos sino acoger todo lo que nos ha pedido don Giulietti, director del servicio Nacional de PJ: "Es necesario que la PV no se preocupe sólo

27 Ibidem, 14.

${ }^{28} \mathrm{CEI}$, Le vocazioni al ministero ordinato e alla vita consacrata nella comunita cristiana, 15.

${ }^{29}$ Ibidem, 34.

30 Ibidem, 28. 
del éxito final del camino de discernimiento y de la eventual vocación al sacerdocio o a la vida consagrada, sino que esté atenta al crecimiento global y armónico de toda la vida del joven". Pero en esto no podemos más que hacer converger nuestras fuerzas. De modo particular, y esto lo verifica constantemente la PV, es indispensable, si queremos que surjan de las vocaciones capaces de superar la usura del tiempo, educar a los jóvenes en el sentido de responsabilidad: "Sigue siendo verdad que para amar como personas adultas, maduras y responsables, se necesita saber asumir toda la responsabilidad de la vida humana: estudio, adquisición de una profesión, compromiso en la comunidad civil. Las experiencias fuertes pueden ayudar tanto cuanto más unen con los caminos ordinarios de la vida, que consisten en el trabajar elegido del que después se es responsable" 31.

- Y para que esto se realice se pide la colaboración por parte de todos, evitando delegar a la PF este compromiso. Sobre todo en familia es necesario que la transmisión de la fe esté acompañada de un estilo de vida cristiano. "En la familia auténticamente cristiana los jóvenes encuentran el ambiente apto para una sana formación humana, afectiva y psicológica, y para una apertura generosa a la vida y al don de sí" 32 . Ella es, en efecto, "el lugar privilegiado de la experiencia del amor, tanto como de la experiencia y de la transmisión de la fe"33. Podremos añadir que es precisamente en la familia donde se encuentra con los primero testimonios de una vida vivida en el amor, como repuesta a una vocación.

\section{¿Con qué propuestas?}

Si no se quiere correr el riesgo de que tantos recursos depositados en el ánimo del joven queden inutilizados a causa de nuestra superficialidad y de un testimonio de vida mediocre, incapaz no sólo de fascinar, sino incluso de hacer que brote alguna petición de sentido, muy frecuentemente no escuchada en el corazón de los jóvenes y de los adultos, es necesario que no nos limitemos a una propuesta genérica, sino que unidos nos empeñemos en acompañarle hasta una adhesión cada vez más plena y consciente al don de la fe y a una respuesta cada vez más acorde con el proyecto de Dios, hasta el punto de que pueda orientar toda su vida. En todo esto "no podemos olvidar el espacio propio de la pastoral juvenil. Si esta sitúa en el centro de la atención y de los programas la persona de Cristo vivo en la Iglesia, el corazón de las chicas y

31 Ibidem, 51.

32 Ibidem, 15.

${ }^{33}$ CEI, Comunicare il Vangelo in un mondo che cambia, 52. 
de los jóvenes se abre a la vocación. O sea a una visión de la vida como respuesta a una llamada. Es necesario proyectar caminos progresivos de formación, que al fin puedan llegar a ser explícitamente vocacionales"34.

- Por esto es indispensable no sólo una mayor colaboración entre PJ y $\mathrm{PV}$, con el respeto de las competencias propias de cada una, sino que la PJ conduzca naturalmente a los jóvenes a plantearse esa pregunta que puede dar sentido y valor a toda su vida: "Señor, ¿qué quieres que haga?"

No podemos menos que recordar lo que se ha escrito en el documento conclusivo del Congreso europeo de vocaciones: "Cuántos jóvenes no han escuchado la llamada vocacional no porque sean poco generosos o indiferentes, sino simplemente porque no han sido ayudados a conocerse, a descubrir la raíz ambivalente y pagana de ciertos esquemas afectivos; y porque no han sido ayudados a liberarse del temor y las defensas, conscientes o inconscientes, en el afrontar la vocación misma... La sinceridad es un paso fundamental para llegar a la verdad, pero es necesario una ayuda externa para ver bien en el interior. El educador vocacional, debe, ahora, conocer los entresijos del corazón humano para acompañar al joven en la construcción de su yo verdadero"35. No debemos tener miedo a hacer propuestas vocacionales claras y radicales. Recordemos: Propuestas vocacionales débiles, generan vocaciones débiles.

\section{¿Dónde?}

No se puede terminar este Congreso, que nos ha visto empeñados en el buscar unidos cualquier forma que pueda favorecer una "mayor coordinación” entre PF, PJ y PV, sin preguntarnos cuál es el lugar en el que se debería realizar sobre todo esta coordinación entre las tres pastorales. La presencia estos días de los Directores nacionales de PF, PJ y PV nos hace intuir inmediatamente que un primer nivel de coordinación es predecible en principio a nivel nacional, desde la cúpula, podríamos decir, si esto no sonase como un distanciamiento de la vida de nuestra comunidad.

Un segundo nivel necesario de coordinación sería deseable realizarlo a nivel regional. A este propósito se ha dicho que algunas regiones tienen de esto buena experiencia, también gracia a la celebración de la JMOV, que ha pedido para su realización la colaboración sobre todo de los responsables regionales de $\mathrm{PJ}$ y $\mathrm{PV}$.

No olvidaremos, sin embargo, que las propuestas pastorales tanto a nivel nacional como a nivel regional deben hacerse necesariamente contando con la

${ }^{34} \mathrm{CEI}$, Le vocazioni al ministero e alla vita consacrata nella comunità cristiana, 24 .

35 NVNE, 35 a. 
vida de nuestras diócesis y, en último análisis, ponerse al servicio de la parroquia. Don Roggia en su Conferencia y Mons. Betori en su introducción a la mesa redonda con los Directores Nacionales de PJ. PF y PV nos han pedido que no prescindamos de una referencia constante a la comunidad parroquial.

La invitación de los Obispos italianos, recordada en este Congreso por Mons. Betori, a "recuperar la centralidad de la parroquia" (CVMC 47) se traduce, sobre todo para nosotros los animadores vocacionales, en el compromiso de estar allí donde la gente vive y no crear áreas "protegidas" o "invernaderos" en los que delimitar la propuesta vocacional para unos pocos "elegidos". "La parroquia es el lugar por excelencia en el que estamos proclamando el anuncio del Evangelio de la vocación y de la vocación de cada uno, tanto que se debe pensar como comunidad vocacional, ministerial y misionera"36.

- En un futuro próximo deberemos necesariamente enfrentarnos con el desafío de realizar la coordinación entre la PF, PJ y PV sobre todo en las parroquias, puede iluminarnos en esto lo que escribía el Papa: "Los diversos componente y miembros de la Iglesia en la Pastoral vocacional harán tanto más eficaz su tarea cuanto más estimulen a la comunidad eclesial como tal, a comenzar desde la parroquia a sentir que el problema de las vocaciones sacerdotales no puede ser delegado de ninguna manera en algunos "encargados" (los sacerdotes en general, los sacerdotes del seminario en especial) porque siendo un problema vital que se sitúa en el corazón de la Iglesia", debe estar en el centro del amor de todo cristiano"37.

Esta coordinación entre la PF, PJ y PV debe empujar decididamente a hacer así que, sobre todo los presbíteros, descubran la alegría del ministerio de acompañamiento espiritual. En la comunidad se advierte una necesidad creciente de iniciadores y de acompañantes en la vida espiritual: los presbíteros deben valorar cada vez más su misión de padre y guía en la vida según el Espíritu, evitando con gran cuidado caer en cierto funcionalismo"38. El logro de este objetivo común evitará que en las parroquias se nos limite al simple anuncio o propuesta vocacional; es indispensable comprometerse también a acompañar a aquellos que han percibido la llamada de Dios y a sostenerle en la respuesta. Todo esto en la profunda convicción de que "Dios nos ha hecho venir a la existencia con su palabra, nos ha pensado y amado desde siempre y llama a cada uno por su nombre"39 (CVMC 26). tiana, 18.

36 CEI, Le vocazioni al ministero ordinato e alla vita consacrata nella comunità cris-

37 Juan Pablo II, Pastores dabo vobis, 41.

38 CEI, Comunicare il Vangelo in un mondo che cambia, 53.

39 Ibidem, 26. 


\section{Conclusiones}

El Director del CNV, don Bonari, en su introducción deseaba que se pasase de un "amor preocupado" hacia los jóvenes a un "amor ocupado".

Será este nuestro compromiso ahora que volvemos a nuestras comunidades, recordando cuanto nos decía Mons. Pitau en su homilía: "Estamos llamados a un amor gratuito, deseado, libre y liberador. No preocupados, por tanto, de nuestras vocaciones, sino de hacer surgir vocaciones en la Iglesia al servicio de los hermanos".

Si nuestro amor no es así nos arriesgaremos a escuchar de los labios de los jóvenes, quizás leer en su rostro lo que decía un poeta francés:

"Tú dices que ame la lluvia y cierre la ventana.

Tú dices que ame las flores y corte su tallo.

Tú dices que ame a los peces y los pesque y los coma.

Por eso, cuando dices que me amas, tengo miedo".

(Tomado de Vocazioni, 20, (03) pp. 70-86) 